Japanese Research on Linguistics, Literature, and Culture Vol. 1 No. 1 Nov. 2018, Hal. 65-78, ISSN: 2655-4836

https://publikasi.dinus.ac.id/index.php/irllc/article/view/2130/1382

Published by Universitas Dian Nuswantoro,

on Linguistics, Literature, and Culture

Jl. Imam Bonjol 207, Semarang

\title{
Konseptualisasi Citra Hara 'Perut’ dalam Idiom Bahasa Jepang
}

\author{
Akhmad Saifudin \\ Universitas Dian Nuswantoro \\ akhmad.saifudin@dsn.dinus.ac.id
}

Article History: Submitted date 2018-11-17; Accepted date 2018-11-28; Published date 2018-11-28

\begin{abstract}
Hara simply means belly, but for Japanese people it means more than physical. Hara is a concept, an important concept related to Japanese human life. This paper discusses the conceptualization of hara image for Japanese people. The study utilizes 25 idioms that contain hara 'belly' word that are obtained from several dictionaries of Japanese idioms. This paper is firmly grounded in cognitive linguistics, which relates linguistic expressions to human cognitive experience. The tool for analysis employed in this paper is the "conceptual metaphor theory" pioneered by Lakoff and Johnson. This theory considers human perception, parts of the body, and people's worldview as the basis for the structure of human language. The analysis of this paper results that metaphorically, hara 'belly' is an entity and a container, which contains important elements for humans, such as life, mind, feeling, mentality, and physical. The concept of hara 'belly' for Japanese people is to have a spiritual, psychological, social and cultural, biological, and physical image.
\end{abstract}

Keywords: conceptualization, conceptual metaphor, hara 'belly', idioms, image 


\begin{abstract}
Abstrak
Secara sederhana hara bermakna perut, namun bagi orang Jepang hara bukan sekedar makna fisik. Hara adalah sebuah konsep, konsep penting yang berkaitan dengan kehidupan manusia Jepang. Makalah ini membahas konseptualisasi citra hara 'perut' bagi orang Jepang. Data yang dianalisis adalah 25 idiom yang mengandung kata hara 'perut' yang diperoleh dari beberapa kamus idiom Jepang. Makalah ini secara kuat didasarkan pada linguistik kognitif, yang mengaitkan ekspresi linguistik dengan pengalaman kognitif manusia. Alat untuk analisis yang digunakan dalam makalah ini adalah "teori metafora konseptual" yang dipelopori oleh Lakoff dan Johnson. Teori ini mempertimbangkan persepsi manusia, bagian tubuh, dan pandangan dunia orang sebagai dasar untuk struktur bahasa manusia. Analisis makalah ini menghasilkan bahwa secara metafora, hara 'perut' adalah entitas dan wadah, yang di dalamnya termuat unsur-unsur penting bagi manusia, seperti kehidupan, pemikiran, perasaan, mentalitas, dan fisik. Konseptualisasi hara 'perut' bagi orang Jepang adalah mempunyai citra spiritual, psikologis, sosial dan budaya, biologis, dan fisik.
\end{abstract}

Kata Kunci: citra, hara 'perut', idiom, konseptualisasi, metafora konseptual

\title{
1. Pendahuluan
}

Mempelajari idiom, utamanya bagi pemelajar bahasa asing, sangatlah sulit. Idiom adalah ungkapan bahasa yang maknanya tidak dapat dipahami hanya dengan makna leksikal dari setiap unsur pembentuk idiom. Gabungan setiap unsur pembentuk idiom memunculkan makna lain. Seringkali pemelajar bahasa asing merasa tidak habis pikir karena begitu sulitnya memahami makna idiom. Mereka sulit menghubungkan antara makna leksikal tiap unsur pembentuk idiom dan makna idiomatisnya. Pembentukan idiom banyak dipengaruhi oleh persepsi, pengalaman, dan penalaran dari penutur asli bahasa.

Idiom disusun tidak dengan bahasa literal, melainkan dengan cara metaforis (Wright, 2002). Metaforalah yang menjadikan makna idiom berbeda. Metafora yang dalam pandangan lama hanya sebagai bahasa figuratif untuk memperindah bahasa, dalam pandangan saat ini dilihat sebagai perwujudan pola pikir manusia yang merupakan konseptualisasi berdasarkan pengalamannya, baik fisik maupun mental, tentang kesamaan antara satu hal dan hal lainnya (Kövecses, 2002; Lakoff \& Johnson, 1980b, 1980a). Teori tentang hal ini disebut teori metafora konseptual. 
Dalam tulisan ini dibahas konseptualisasi makna hara 'perut' dalam idiom bahasa Jepang. Menurut Yu, metafora timbul berdasarkan interaksi antara tubuh dan kebudayaan (2008). Salah satu bagian tubuh yang banyak digunakan dalam idiom bahasa Jepang adalah hara 'perut'. Konsep hara menarik dikaji karena salah satunya dipakai dalam ungkapan ikonik Jepang, yakni hara-kiri 'bunuh diri seorang Samurai dengan cara menyobek bagian perut dengan pedang'. Kita tentu bertanya, mengapa harus bagian perut, bukan bagian lain yang lebih mematikan seperti dada atau leher? Sebenarnya apa makna perut bagi orang Jepang?

\subsection{Teori Metafora Konseptual}

Metafora konseptual adalah kerangka teoretis yang dikembangkan pertama kali oleh George Lakoff dan Mark Johnson melalui buku mereka yang berjudul Metaphors We Live by pada tahun 1980. Konsep ini sejalan dengan pandangan Zoltán Kövecses (2002), Raymond Gibbs (2004), dan Mark Turner (1998). Mereka memandang bahwa metafora sebenarnya bukan sekedar fenomena bahasa, lebih dari itu adalah sebuah pola bagaimana penalaran/kognitif manusia membuat konsep akan suatu hal. "the locus of metaphor is not in language ... but in the way we conceptualize one mental domain in terms of another" (Lakoff, 2006). Hal Ini berarti bahwa ekspresi kognitif manusia dapat juga melalui media nonverbal.

Teori metafora konseptual menyatakan bahwa "esensi metafora adalah pemahaman dan pengalaman satu jenis hal ke dalam hal lain" (Lakoff \& Johnson, 1980a). Berkenaan dengan strukturnya, metafora konseptual ditandai oleh pemetaan parsial sistematis yang bersifat undirectional dari domain sumber ke domain target (Evans \& Green, 2006; Kövecses, 2002; Lakoff \& Johnson, 1980b; Saeed, 2003; Saifudin, 2012; Swasono, 2013; Swasono \& Saifudin, 2013). Istilah domain mengacu pada "sebuah tubuh pengetahuan yang mengatur konsepkonsep terkait" (Evans \& Green, 2006), dalam hal ini “domain sumber lebih bersifat fisik/konkrit dan domain target abstrak atau samar" (Kövecses, 2002). Dengan begitu dapat disimpulkan bahwa metafora adalah sebuah fasilitas untuk memahami domain target yang abstrak dan sulit dijelaskan melalui domain sumber yang lebih nyata dan konkrit. Sebagai contoh dalam metafora LOVE IS JOURNEY, LOVE adalah domain target yang bersifat abstrak dijelaskan melalui domain sumber, yakni JOURNEY yang bersifat lebih nyata. LOVE dan JOURNEY adalah dua domain yang berbeda, LOVE merupakan domain perasaan kasih sayang yang dimiliki manusia 
terhadap seseorang/sesuatu, sedangkan JOURNEY adalah aktifitas pergerakan yang mempunyai titik awal dan titik akhir. Menjelaskan perasaan cinta yang sifatnya abstrak akan lebih sulit jika dibandingkan dengan menjelaskan konsep perjalanan yang sifatnya lebih nyata. Kemiripan LOVE dan JOURNEY dapat dilihat dari ekspresi linguistik yang terdapat dalam kedua konsep tersebut. Sebagai contoh adalah dalam ekspresi "Cintaku padamu tidak akan pernah berakhir". Kata berakhir adalah salah satu unsur yang ada dalam domain perjalanan. Dari sini tampak bahwa konsep cinta yang abstrak dapat dikonkritkan dengan konsep perjalanan, sehingga seakan-akan cinta itu dapat diukur layaknya sebuah perjalanan.

Lakoff dan Johnson (1980b) membagi metafora menjadi tiga jenis, yakni struktural, orientasional, dan ontologikal. Metafora jenis pertama, yakni struktural merepresentasikan penggunaan struktur domain ke dalam domain yang lain. Domain sumber biasanya menyediakan struktur yang relatif lebih kaya sehingga mudah dipahami untuk merepresentasikan domain target. Sebagai contoh, metafora ARGUMENT IS WAR memberikan satu contoh metafora struktural, yakni konsep argumen disusun relatif terhadap konsep perang. Pemetaan lintas-domain yang terlibat dalam metafora ini tidak hanya menjelaskan makna dari realisasi linguistik individualnya (yaitu ekspresi metafora), tetapi juga untuk pemahaman konsep sebuah argumen dan esensinya.

Metafora jenis yang ke dua, yakni orientasional memberikan sebuah konsep orientasi spasial. Orientasi spasial ini muncul berdasar pengalaman fisik manusia yang berkaitan dengan orientasi arah dalam kehidupan sehari-hari. Pengalaman tersebut dijadikan sebagai pedoman yang terpatri dalam pikiran manusia, misalnya membuat ukuran yang lebih konkrit dengan menggunakan dimensi naik-turun (UP-DOWN). Contoh yang lain adalah HAPPY IS UP - SAD IS DOWN; GOOD IS UP - BAD IS DOWN.

Metafora ontologis "melibatkan proyeksi entitas atau status substansi pada sesuatu yang tidak memiliki status itu secara inheren" (Lakoff \& Johnson, 1980b: 196). Dengan kata lain, "metafora ontologis memungkinkan kita untuk melihat struktur yang lebih jelas dan terdefinisi yang mana di dalam domain target hanya terdefinisikan sangat sedikit atau tidak sama sekali" (Kövecses, 2010). Sebagai contoh dalam metafora INFLATION IS AN ENTITY; THE MIND IS A MACHINE; dan THE MIND IS A CONTAINER, memungkinkan kita untuk memahami beberapa 
konsep abstrak, tidak berwujud, dengan mengandalkan pengalaman kita dengan objek fisik, sehingga seolah-olah kita dapat menunjuk, mengukur, dan memberikan pemerian dari suatu konsep yang sebenarnya abstrak.

\subsection{Skema Citra}

Dalam linguistik kognitif untuk menekan pentingnya kategorisasi digunakan sebuah gagasan yang disebut skema citra. Skema citra adalah "pendeskripsian kembali secara ringkas pengalaman perseptual untuk tujuan pemetaan struktur spasial ke dalam struktur konseptual" (Oakley, 2007: 215). Dengan kata lain, skema citra merepresentasikan struktur prakonsepsi yang berasal dari pola interaksi tubuh sehari-hari yang menyediakan perancah untuk sistem konseptual kompleks yang mengatur kognisi manusia. Dengan bahasa yang lebih mudah, skema citra adalah citra yang dibentuk oleh kognisi manusia berdasarkan pengalamannya selama berinteraksi dengan berbagai hal dalam kehidupannya. Johnson (1987: 126 dalam Oakley, 2007) telah membuat daftar skema citra sebagai berikut: container; balance; compulsion; blockage; counterforce; restraint removal; enablement; attraction; masscount; path; link; center-periphery; cycle; near-far; scale; part-whole; merging; splitting; full-empty; matching; superimposition; iteration; contact; process; surface; object; collection.

\subsection{Metode Penelitian}

Data penelitian yang berupa ungkapan hara 'perut' yang terdapat dalam idiom bahasa Jepang dikumpulkan dari sumber data utama berupa kamus on-line WEBLIO Jiten (https://www.weblio.jp/phrase/\%E8\%85\%B9 3). Data lain diperoleh dari peribahasa dan hasil wawancara dari seorang nara sumber. Dari proses pengumpulan data diperoleh total data,

yakni idiom yang mengandung unsur hara 'perut' sebanyak 25 data. Data yang terkumpul kemudian diidentifikasi, dikategorisasi berdasarkan teori metafora konseptual untuk menentukan skema citra dan makna hara 'perut' bagi orang Jepang.

\section{Hasil dan Pembahasan}

\subsection{Makna Literal Hara 'Perut”}

Hara 'perut' jika ditulis dengan karakter Kanji adalah 腹. Karakter 腹 dibaca secara kunyomi (cara baca Jepang) hara, dan secara on-yomi (cara baca Cina) fuku. Dalam kamus Kokugojiten ditemukan makna hara 'perut' sebagai berikut. 
1. 胸から腰の間で中央にへそがある前面の部分。横隔膜と骨盤の間で、胃腸のある 部分。腹部。[Mune kara koshi no made chuo ni heso ga aru zenmen no bubun. Okakumaku to kotsuban no made, icho no aru bubun. Fukubu. 'Bagian depan di antara dada dan pinggang yang di tengahnya terdapat pusar. Bagian yang terdapat saluran gastrointestinal/saluran lambung dan usus di antara diafragma dan panggul. Abdomen.]

2. 胃腸。[/cho'saluran lambung dan usus]

3. 胎。[Hara' 'rahim']

4. 胆。 $[$ Tan 'empedu']

Dapat disimpulkan bahwa makna hara adalah bagian tubuh manusia yang berada di tengah tubuh secara vertikal di antara dada dan pinggang, yang bagian depannya terdapat pusar. Termasuk dalam cakupan makna hara adalah bagian dalam perut, yang terdiri dari organ-organ dalam seperti usus, lambung, ginjal, hati (liver), dan empedu.

\subsection{Konseptualisasi Citra Hara 'Perut'}

Berdasarkan unsur hara dalam idiom bahasa Jepang yang ditemukan dari sejumlah data, maka dapat diperoleh simpulan bahwa konsep hara bagi orang Jepang adalah HARA IS A CONTAINER. Hara secara metaforis mempunyai kemiripan dengan sebuah wadah dari segi bentuk dan fungsinya. Wadah adalah sebuah tempat yang berfungsi untuk menaruh, menyimpan, menghimpun, atau memuat sesuatu. Oleh karena hara adalah wadah, maka secara metaforis dapat dikatakan juga SOMETHING IN THE HARA IS AN ENTITY. Apa yang terdapat di dalam hara adalah sebuah entitas. Secara metonimi hara juga merefleksikan apa yang termuat di dalam hara, yakni entitas yang merefleksikan konsep hara bagi orang Jepang.

\subsubsection{Hara adalah sumber kehidupan}

Hara dianggap sebagai sumber kehidupan nampak dari data idiom (1) hara-kiri atau (2) seppuku. Keduanya bermakna literal memotong perut. Hara-kiri atau yang dikenal pada zaman samurai sebagai seppuku adalah ritual bunuh diri yang dilakukan seorang samurai dengan sukarela yang lebih memilih mati secara terhormat dari pada jatuh ke tangan musuh, atau sebagai bentuk hukuman mati untuk samurai yang telah melakukan pelanggaran serius, atau dilakukan karena telah melakukan perbuatan memalukan yang merusak harga diri (Szczepanski, 2017). Aktifitas ini adalah murni simbolis karena sebenarnya bunuh diri dapat dilakukan dengan 
cara yang lain yang mungkin lebih sederhana dan mematikan. Dengan memotong atau menusukkan pedang ke perut, orang tidak akan seketika mati. Orang tersebut akan merasakan sakitnya perut ditusuk pedang. Itulah sebabnya dalam praktik seppuku ada seseorang yang berdiri di belakang pelaku seppuku yang siap memenggal kepala pelaku jika perutnya sudah terbelah. Tindakan ini dilakukan untuk menyelamatkan muka pelaku dari kematian yang lama dan mencegah adanya rintihan.

Mengapa perut? Ini yang menarik dibahas. Secara fisik perut punya peran penting untuk menopang kehidupan. Di dalam perut terdapat organ-organ yang terutama berfungsi sebagai alat pencernaan, seperti usus, lambung, hati, dan pankreas. Makanan sebagai sumber tenaga, diproses dan disimpan dalam perut. Ketika bayi masih di dalam rahim, ia dapat hidup karena suplai makanan ibunya yang disalurkan melalui pusar yang ada di perut. Apabila perut dipotong maka rusaklah organ penting untuk hidup sehingga dapat menyebabkan kematian. Namun, memotong perut bukanlah cara yang paling efektif untuk membunuh. Ada organ lain yang lebih efektif, misalnya jantung atau leher.

Dalam sejarah budaya Jepang, perut memiliki makna yang penting dalam kehidupan orang Jepang. Pada zaman samurai, kehidupan Jepang banyak dipengaruhi oleh Cina. Ajaran religi yang berkembang adalah Budha-Zen. Dalam ajaran ini perut dipercaya sebagai pusat kehidupan, kekuatan, dan di dalamnya terdapat sesuatu yang sakral. Dalam pengobatan tradisional Jepang, sumber pengobatan utama adalah di perut. Kita juga dapat melihat bahwa teknik pernafasan perut juga menjadi bagian penting dalam ritual-ritual upacara minum teh, olah raga tradisional, seperti sumo dan judo, dan ritual keagamaan ketika bersemedi. Dengan memotong perut berarti membedah wadah untuk mengeluarkan apa yang termuat di dalamnya. Secara simbolis apa yang ada di dalam perut diyakini oleh orang Jepang sebagai entitas penting untuk kehidupan. Dengan keluarnya isi dari perut maka hilanglah unsur-unsur kehidupannya. Dengan demikian dapat disimpulkan bahwa hara mempunyai makna religius yang berhubungan dengan keyakinan orang Jepang terhadap hara sebagai sumber kehidupan.

\subsubsection{Hara adalah perasaan/emosi}

Citra hara sebagai perasaan atau emosi terdapat dalam beberapa contoh idiom berikut.

(3) hara ni osameru memasukkan di dalam perut 'menahan marah'; 
(4) hara ni tsuekaneru tidak bisa menyimpan di dalam perut 'tidak bisa menahan marah';

(5) hara ga ieru perut sembuh 'reda kemarahannya';

(6) hara ga tatsu perut berdiri/naik 'marah'.

Dari data (3) dan (4) kita dapat melihat bahwa hara adalah tempat bersemayamnya emosi manusia. Konsep metafora untuk kondisi ini adalah metafora ontologikal HARA IS THE CONTAINER OF EMOTIONS. Emosi kemarahan letaknya ada di dalam hara, karena itu agar tidak marah orang harus tetap menjaganya atau memasukkannya ke dalam hara. Sementara di data (5) dapat dilihat bahwa perutnya sembuh bermakna reda kemarahannya. Ini berarti bahwa hara adalah representasi dari apa yang termuat di dalamnya. Jika isi dari perut bergejolak maka yang timbul adalah kemarahan. Kemarahan akan reda jika kondisi perut sudah tenang dan stabil.

Data (6) situasinya lebih menarik lagi. Mengapa perut berdiri? Apa bisa perut berdiri? Kenapa mempunyai makna marah? Untuk mendalami situasi ini maka harus dipahami konsep orang Jepang tentang marah yang berkaitan dengan anggota tubuh. Terdapat tiga anggota tubuh yang berkaitan dengan marah, yakni hara 'perut', mune 'dada', dan atama 'kepala'. Secara posisi di tubuh manusia, hara berada di bawah mune, dan yang paling atas adalah atama. Ketika orang mulai marah, ia akan mencoba mengontrolnya dengan menjaganya tetap berada di dalam perut (3). Jika tidak bisa menahan untuk tetap di perut (4), kemarahan akan naik menuju dada. Kondisi ini dapat dilihat pada ungkapan Haradatashisa ni mune o shimetsukerareru 'dadanya sesak karena naiknya perut' (Matsuki, 1995). Apabila kondisi marahnya semakin meningkat dan tidak terkendali oleh rasio maka toutou ni atama ni kita 'akhirnya sampai ke kepala'. Kata tatsu 'berdiri' menunjukkan aktifitas dari bawah ke atas, yakni dari dalam perut (tempat bersemayamnya emosi), menuju ke dada dan kepala. Ini adalah jenis metafora orientasional UP/DOWN, UP IS HOT AND TENSION dan DOWN IS COOL AND PEACE.

\subsubsection{Hara adalah pikiran, watak dan kalbu/hati nurani}

Kata pikiran bermakna hasil berpikir, akal, ingatan, angan-angan, niat, dan maksud (Https://kbbi.web.id/watak, n.d.). Watak adalah sifat batin manusia yang mempengaruhi 
segenap pikiran dan tingkah laku; budi pekerti; tabiat (Https://kbbi.web.id/watak, n.d.) . Sementara makna kalbu menurut KBBI adalah pangkal perasaan batin; hati yang suci (murni); hati (Https://kbbi.web.id/watak, n.d.) dan makna hati nurani adalah perasaan murni yang sedalam-dalamnya (Https://kbbi.web.id/hati, n.d.). Makna hara yang merepresentasikan pikiran, watak, dan kalbu/hati nurani dapat dilihat pada idiom-idom sebagai berikut.

(7) hara ga ookii perutnya besar 'berwawasan luas/berpikir terbuka'

(8) hara ga kuroi hatinya hitam 'wataknya jahat'

(9) hara ga katai perutnya keras 'memegang teguh prinsip/pendirian'

(10) hara wo waru membagi/membelah perut 'mendasarkan pada hati nurani'

(11) hara wo yomu membaca perut 'menerjemahkan maksud seseorang'

(12) hara ga miesuiteiru perutnya transparan 'maksud sebenarnya sangat jelas'

(13) hara ga mirareru perutnya nampak 'yang ada dalam pikiran seseorang kelihatan'

(14) hara ga wakaranai tidak mengerti perutnya 'tidak mengerti maksud sebenarnya'

(15) hara wo saguru mencari perut 'usaha menemukan maksud yang sesungguhnya'

(16) hara wo minuku melihat melalui perut 'melihat maksud sebenarnya'

Keseluruhan data dari (7) sampai dengan (16) menunjukkan konsep metafora HARA IS A CONTAINER. Perut adalah wadah, yakni yang mewadahi sesuatu yang bersifat mendasar, murni, yang sebenarnya, yang menjadi inti, jati diri, dan tidak kasat mata. Ini adalah metafora ontologikal yang merepresentasikan sesuatu yang abstrak, kasat mata, tidak terukur dengan sesuatu yang konkret yang terdapat dalam perut. Hara adalah wadah yang melindungi, atau lebih tepatnya menyembunyikan kondisi yang sebenarnya dari manusia. Apabila dikaitkan dengan salah satu konsep budaya Jepang tentang honne 'diri pribadi' dan tatemae 'diri sosial', maka metafora hara adalah honne, sesuatu yang disembunyikan karena sesuatu hal (misal untuk menjaga harmoni sosial). Yang dihadirkan di muka umum adalah tatemae, yakni diri sosial yang dihadirkan ketika berinteraksi dengan 'diri' orang lain (Saifudin, 2007).

Citra hara yang merepresentasikan pikiran dapat dilihat dalam idiom (7) Hara ga ookii 'perutnya besar'. Ini adalah metafora ontologikal dengan hara 'perut' dideskripsikan menggunakan ajektiva untuk menyatakan ukuran. Makna metaforis dari hara ga ookii adalah 
orang yang berwawasan luas dan berpikir terbuka. Konsep HARA IS A CONTAINER digambarkan sebagai wadah yang besar yang mampu menampung banyak pengetahuan dan wawasan, dan sebaliknya wadah yang kecil tidak mampu memuat banyak. Dengan demikian, pikiran yang kita kenal berada di otak/kepala (secara universal, terutama Barat), bagi orang Jepang dapat direpresentasikan dengan perut. Masalah ilmu pengetahuan dalam hal ini bukan hanya sebagai aktifitas akal (rasio/otak/kepala) manusia belaka, melainkan menjadi sebuah kebijaksanaan dari manusia yang berpusat di perut. Apa yang ada di perut dalam kaitannya dengan pikiran, bagi orang Jepang lebih fundamental dari sekedar pemikiran di kepala (Durckheim, 1977).

Dalam kaitannya dengan watak, dapat dilihat pada data (8) dan (9). Hara diekspresikan sebagai sebuah wadah atau entitas yang dapat dideskripsikan dengan ajektiva seperti, kuroi 'hitam' dan katai 'keras'. Hitam dalam banyak budaya, termasuk Jepang mempunyai konotasi yang tidak baik, seperti kotor, antonim dari putih yang melambangkan kesucian dan kemurnian, dan gelap yang biasanya berkorespondensi dengan kejahatan. Sehingga perut yang hitam merepresentasikan niat atau watak jahat yang ada pada diri seseorang. Di data (9) hara dideskripsikan dengan ajektiva katai yang berarti keras atau kaku. Kata katai 'keras' dapat berkonotasi positif dan negatif, dan dalam idiom ini bermakna orang yang mempunyai watak/pendirian yang keras, teguh, dan tidak mudah berubah.

Data (10) sampai dengan (16) hara diekspresikan sebagai wadah, alat, entitas yang berhubungan dengan kalbu/hati nurani, yakni perasaan hati yang yang paling dalam, dasar, dan yang sebenarnya. Dalam bahasa Inggris dapat berkorespondensi dengan istilah heart dan dalam bahasa Indonesia dengan istilah 'hati'. Heart dan hati di sini bukanlah makna secara fisik. Ini adalah simbol ataupun konsep yang merepresentasikan perasaan. Meskipun tidak bisa dipungkiri istilah heart atau hati seringkali ditunjukkan dengan gesture menunjuk pada dada, atau lebih tepatnya organ Jantung yang terletak di dalam dada. Lucunya, di dalam bahasa Indonesia terdapat organ dalam yang disebut hati (liver dalam bahasa Inggris) yang terletak di dalam perut, tetapi kalau merujuk pada perasaan manusia yang ditunjuk adalah dada. Di sini hara mencerminkan suatu keinginan murni atau maksud yang sebenarnya yang terdapat di hati nuraninya. 
Dalam konsep psikologis dan sosial budaya Jepang juga dikenal istilah kokoro. Kokoro bagi orang Jepang adalah tempat di mana perasaan berada (Hasada, 2002). Dalam bahasa Inggris istilah kokoro sering disamakan dengan istilah heart 'hati' dan mind 'pikiran'. Namun, bagi orang Jepang kokoro lebih dari itu, ia mempunyai cakupan yang lebih luas, yakni mencakup makna perasaan, pemikiran, jiwa, ruh, dan juga mentalitas ("What is Kokoro?: The Concept of Kokoro," n.d.). Menurut Miyakoshi (1989:47) tubuh itu terdiri dari karada dan kokoro (dalam Hasada, 2002). Karada bermakna badan atau tubuh secara fisik, sementara kokoro sebaliknya bermakna nonfisik/abstrak. Dalam bahasa atau penjelasan yang mungkin lebih mudah dipahami untuk zaman sekarang adalah dengan membandingkan dengan komputer, karada adalah hardware dan kokoro adalah softwarenya. Karada bersifat jasmani/ragawi dan kokoro bersifat rohani. Karena kokoro bersifat nonfisik, tidak mudah untuk menunjukkan letak yang tepat di mana kokoro berada. Namun yang jelas dari ungkapan-ungkapan dan idiom-idiom bahasa Jepang yang mengandung unsur kokoro, nampak bahwa lokus kokoro berada di rongga mune 'dada' dan hara 'perut' secara konsep. Dengan demikian secara metaforis dapat dikonsepkan bahwa HARA AND MUNE IS CONTAINER OF KOKORO.

\subsubsection{Hara adalah tekad/keberanian mengambil tindakan}

(17) hara ga suwaru perutnya duduk 'tidak cemas/khawatir terhadap apa yang dihadapi' (18) hara ga dekiteiru perutnya sudah komplet 'siap menangani sesuatu'

(19) hara wo kimeru memutuskan perut 'bertekad berhasil dalam menangani sesuatu' (20) hara de iku pergi dengan perut 'bertindak berani'

Hara dalam data (17) sampai dengan (20) berhubungan dengan pengambilan keputusan. Keputusan yang diambil dengan hara adalah keputusan yang dibuat dengan tekad dan berani, tidak cemas dengan apa yang akan terjadi karena hara 'perut'nya sudah siap. Hara di sini adalah CONTAINER atau ENTITY, tempat orang mengambil keputusan, tempat di mana keberanian dan mentalitas berada.

\subsubsection{Hara adalah Rahim}

Makna hara yang merujuk pada rahim adalah berdasarkan letak rahim yang berada di dalam perut. Dengan demikian hara sebagai rahim adalah sebuah metonimi CONTAINER 
REPRESENTS THE CONTAINED. Namun karena makna rahim yang direpresentasikan oleh perut bukan makna literal, maka dapat diidentifikasi sebagai metafora dengan domain sumbernya adalah rahim dan domain targetnya perut. Idiom hara yang mempunyai konsep metafora yang merepresentasikan rahim adalah sebagai berikut.

(21) harachigai no kyoodai saudara beda perut 'saudara tidak seibu/sekandung'

(22) hara wo itameta kodomo anak yang menyakiti perut 'anak biologis'

Di data (21) dan (22) perut mempunyai konsep metafora HARA IS A WOMB, perut adalah rahim tempat bayi dikandung ibunya sebelum dilahirkan. Dalam (21), harachigai 'beda perut' menjelaskan rahim dari ibu yang berbeda, sementara di data (22) hara wo itameta 'menyakiti perut' menggambarkan peristiwa lahirnya seorang anak yang membuat ibunya kesakitan karena melahirkan.

\subsubsection{Hara adalah kondisi fisik}

Beberapa ekspresi hara menjelaskan keadaan atau kondisi fisik dari perut. Ini adalah metafora ontologikal yang diperoleh berdasarkan pengalaman, terutama pengalaman terkait bagian tubuh dalam kehidupan manusia. Tercakup dalam metafora ini adalah idiom-idiom sebagai berikut.

(23) hara ga kita perutnya telah datang 'lapar'

(24) hara ga kudaru perutnya turun 'sakit diare'

(25) hara wo kakaeru melipat perut 'tertawa terbahak-bahak'

Pada data (23) hara adalah sebuah wadah tempat makanan disimpan dan dicerna di dalam tubuh. Sebagai sebuah wadah harusnya ada isi di dalamnya, yakni makanan. Jika makanan yang berada di dalam perut habis maka yang terjadi adalah rasa lapar karena wadahnya perlu diisi. Rasa lapar telah datang direpresentasikan dengan hara ga kita 'perut telah datang'. Kemudian pada (24) hara secara ontologikal adalah sebuah wadah, yakni wadah makanan, juga tempat makanan dicerna. Kudaru berarti turun, yang menjelaskan orientasi spasial dari hara. Dalam metafora orientasional, hal-hal yang pada dasarnya baik untuk manusia, termasuk kesehatan, pada umumnya adalah UP (Lakoff \& Johnson, 1980b). Metafora orientasionalnya adalah HEALTH IS UP; SICKNESS IS DOWN. Sakit Diare dalam bahasa Jepang disebut geri, yang mana ge dalam istilah tersebut ditulis dengan karakter kanji 下 yang berarti 
turun/bawah, karakter yang sama untuk menuliskan kudaru. Pada data (25), idiom tersebut menggambarkan kondisi seseorang yang sedang tertawa terbahak-bahak perutnya seperti terlipat atau tertekuk. Kondisi perut ini membentuk metafora ontologikal bahwa perut yang terlipat adalah orang yang sedang tertawa terbahak-bahak. Apa yang menarik di sini adalah bahwa pada umumnya di bahasa atau budaya yang lain penggambaran kondisi tertawa terbahak-bahak biasanya dengan merepresentasikan penekanan pada bunyinya, bukan pada perutnya.

\section{Simpulan}

Dalam makalah ini telah dibahas ekspresi bahasa Jepang hara yang terdapat dalam idiom dan makna metaforanya. Dapat dilihat bahwa ternyata bagian tubuh, dalam hal ini adalah hara 'perut', telah digunakan sebagai bahan untuk memproduksi eskspresi-ekspresi baru yakni dalam bentuk metafora. Bagian tubuh menjadi sumber yang kaya untuk mengkonseptualisasi ekspresi metafora. Konsep-konsep yang diungkapkan dalam metafora berhubungan dengan ciri-ciri budaya, interaksi sosial, pengalaman alami dan domain dasar kehidupan manusia, termasuk persepsi dan gerakan tubuh, objek dasar dan lingkungan. Makalah ini menetapkan bahwa ekspresi bagian tubuh akan mengungkapkan hal-hal yang berhubungan dengan dunia yang diperoleh berdasarkan pengalaman dan pengetahuan, dan bahwa mereka adalah sumber konseptual terkaya untuk berbicara tentang dunia.

Dari hasil pembahasan, dapat diketahui bahwa secara metafora, hara 'perut' adalah sebuah entitas dan wadah. Hara 'perut' sangat berkaitan erat dengan keyakinan spiritual, pemikiran, perasaan, mentalitas, dan kondisi fisik. Sehingga dapat dikatakan bahwa bagi orang Jepang hara mempunyai citra spiritual, psikologis, sosial dan budaya, biologis, dan fisik.

\section{Daftar Pustaka}

Durckheim, K. G. Von. (1977). Hara: The Vital Centre of Man (1985th ed.). London: George Allen \& Unwin.

Evans, V., \& Green, M. (2006). Conceptual blending. Cognitive Linguistics: An Introduction, 190(April), 400-444. https://doi.org/10.1007/BF02356963

Fauconnier, G., \& Turner, M. (1998). Conceptual integration networks. Cognitive Science, 22(2), 133-187. https://doi.org/10.1207/s15516709cog2202_1

Gibbs, R. W., Costa Lima, P. L., \& Francozo, E. (2004). Metaphor is grounded in embodied 
experience. Journal of Pragmatics, 36(7), 1189-1210. https://doi.org/10.1016/j.pragma.2003.10.009

Hasada, R. (2002). 'Body part' terms and emotion in Japanese. Pragmatics \& Cognition, 10(1-2), 107-128. https://doi.org/10.1075/pc.10.12.06has

Https://kbbi.web.id/hati. (n.d.). Arti kata hati - Kamus Besar Bahasa Indonesia (KBBI) Online. Retrieved November 10, 2018, from https://kbbi.web.id/hati

Https://kbbi.web.id/watak. (n.d.). Arti kata watak - Kamus Besar Bahasa Indonesia (KBBI) Online. Retrieved November 7, 2018, from https://kbbi.web.id/watak

Kövecses, Z. (2002). Metaphor: A Practical Introduction. New York: Oxford University Press.

Kövecses, Z. (2010). Metaphor: A Practical Introduction. English Linguistics / Journal of the English Linguistic Society of Japan, 22(1), 205-231. https://doi.org/10.1023/A:1023919116538

Lakoff, G. (2006). Conceptual Metaphor: The contemporary theory of metaphor. In D. Geeraerts (Ed.), Cognitive Linguistics: Basic Readings (pp. 185-238). Berlin: Mouton de Gruyter.

Lakoff, G., \& Johnson, M. (1980a). Conceptual Metaphor in Everyday Language. The Journal of Philosophy, 77(8), 453. https://doi.org/10.2307/2025464

Lakoff, G., \& Johnson, M. (1980b). Metaphors We Live by. London/Chicago: The University of Chicago Press.

Matsuki, K. (1995). Metaphors of anger in Japanese. In J. R. Taylor \& R. E. M. Editors (Eds.), Language and the Cognitive Construal of the World (pp. 145-159). Berlin-New York: Mouton de Gruyter.

Oakley, T. (2007). Image Schemas. In D. Geeraerts \& H. Cuykens (Eds.), The Oxford Handbook of Cognitive Linguistics (pp. 214-235). Oxford - New York: Oxford University Press.

Saeed, J. I. (2003). Semantics (2nd ed.). Malden: Blackwell Publising.

Saifudin, A. (2007). Ekspresi "diri" dalam bahasa Jepang. Lite, 3(1), 1-10.

Saifudin, A. (2012). Metafora dalam Lirik Lagu Kokoro no Tomo Karya Itsuwa Mayumi. LITE, 8(2), 89-105.

Swasono, R. N. (2013). Metafora dalam Idiom Bahasa Jepang yang Mengandung Unsur 花 dan 猫. Universitas Dian Nuswantoro.

Swasono, R. N., \& Saifudin, A. (2013). Makna Idiom Hana dalam Perspektif Budaya Orang Jepang. In Simposium Nasional ASJI (pp. 1-15). Semarang: Universitas Dian Nuswntoro.

Szczepanski, K. (2017). Learn About Seppuku, a Form of Ritual Suicide. Retrieved November 5, 2018, from https://www.thoughtco.com/seppuku-definition-195157

What is Kokoro?: The Concept of Kokoro. (n.d.). Retrieved November 10, 2018, from https://www.kendo-guide.com/what-is-kokoro-the-concept-of-kokoro.html

Wright, J. (2002). Idioms organiser: Organised by metaphor, topic and key word. (J. Hill \& M. Lewis, Eds.). Boston: Thomson. Heinle.

Yu, N. (2008). Metaphor from body and culture. In R. W. Gibbs (Ed.), The Cambridge Handbook of Metaphor and Thought (pp. 247-261). Cambridge: Cambridge University Press. 